\title{
Values and the Use of Community Services
}

\section{Sharon King \\ Clare Collins Michelle Liken}

Objective factors have traditionally been used to study service use. Difficulty in explaining variability in service use has resulted in suggestions that thought be given to subjective factors. Difficulty in isolating subjective factors led to this study of the types of values that influence the use of community services by caregivers of persons with dementing disease. Persons who care for family members who have dementing diseases face an arduous task that has been described as requiring a "36-hour day" but report low rates of community service use. A content analysis was conducted of interview responses of 34 caregivers of a relative with dementia. Three major value concepts were identified: family obligation, reciprocity, and the need for control. Matrices were then developed to explore potential links between expressed values and patterns of use of community services. Implications for clinical practice and research are presented.

Within the fields of gerontology and family caregiving some areas of study have become so well documented that they now only require

Authors' Note: This research was supported by a grant from the Alzheimer's Association/Beverly C. Duchossis Pilot Research Grant, Sharon King, Principal Investigator and a grant from the National Institute of Mental Health: "Impact of Alzheimer's Disease on Family Caregivers" (2R01-MH4 1766-03), Clare Collins, Principal Investigator. The authors would like to acknowledge the thoughtful and helpful review of this manuscript by Barbara Given, C. W. Given, Joanne Pohl, and Manfred Stommel. 
acknowledgement. The trend that has been observed over the past few decades reveals a population in the United States that is becoming older and with the increase in age there has been a corresponding increase in reported disability and frailty. It is also generally understood that families are the major providers of assistance to dependent elders and that providing assistance may result in a variety of stresses within the family. Community services exist that have the potential of aiding families in their caregiving roles but service use is frequently documented as being low. The responsibilities shouldered by those families who have a member with a dementing disease are particularly intense, yet these families have been shown to exhibit characteristically low rates of service use.

One factor that has not been acknowledged to any great extent in service use research is the value system of those families who may have reason to use community services. In a review of the inconclusive findings of four major studies of predictors of community service use by the elderly, McCaslin (1988) calls for increased attention to the influence of individual attitudes to expand understanding of service use. Studies that focused only on "patient need" have demonstrated poor predictive power in estimating use of community services.

Values, for the purpose of this analysis, are defined as "internalized criteria by which people select and judge their own and others' goals and behaviors in society" (McPherson, 1990). An increased understanding of the expressed values of family members involved in providing care for a dependent elder should result in greater insight about potential users of community services.

The purpose of this article is to describe the categories of values expressed by caregivers of older family members with a dementing disease and to examine how those values relate to their use of community services such as home health aides, adult day care, and support groups.

\section{REVIEW OF THE LITERATURE}

With an ever increasing number of families involved in the provision of assistance to dependent elders in the community, there has been a growing interest in understanding the use of both medical and community services over the past two decades. The most predominant 
body of research has investigated the use of medical services (Andersen \& Newman, 1973; Branch et al., 1980) and more recently studies have also been conducted to learn more about the factors that influence elders and their families to use community services. Most of the research that has been reported to date has focused on the concrete objective characteristics of patients, their caregivers, or both in an attempt to predict service use. There have been studies of the physical and functional status of the elder for whom service is intended, as well as the severity of their illness (Bass \& Noelker, 1987) and, additionally, studies of the sociodemographic characteristics of family members who take primary responsibility for care of elders (Bass \& Noelker, 1987). These studies have accounted for only a small portion of variance in service use.

Caregivers of persons with dementing diseases represent a group of individuals who are faced with care demands that persist over a period of years and result in high levels of physical and emotional strain (Given, Collins, \& Given, 1988). Although it might logically be hypothesized that the physical and emotional strain would translate into high need for assistance, the usage of community services by caregivers of dementia patients has been consistently documented as being lower than that found in groups of family members caring for persons with physical disabilities (Collins, Stommel, King, \& Given, 1991). Until subjective characteristics are examined an incomplete understanding of the issues that serve to facilitate or hinder use of community services for any group of caregivers will persist. Those subjective characteristics appropriate for study remain illusive because they are based on perceptions of caregivers that are abstract and have not been articulated in the literature. In an effort to identify caregiver perceptions of importance the work of Ajzen and Fishbein (1980) was examined.

Ajzen and Fishbein (1980) hypothesized a theory of reasoned action based on the assumption that people are rational and make reasoned decisions about their behaviors. Within this theory, beliefs and values are postulated to influence a person's attitudes and perceptions of social norms, which in turn serve to influence their intent to carry out a behavior. As hypothesized by this theory it is inappropriate to assume that beliefs and values may be used to directly predict behavior, but rather set the stage for an increased understanding of human help-seeking behaviors. 


\section{METHOD}

\section{Sampling Procedure}

Participants for this qualitative study were selected from participants in a longitudinal survey. The survey participants $(n=180)$ were a volunteer nonrandom group of caregivers who were recruited for a 5-year longitudinal study of the experience of providing care to a family member with Alzheimer's disease. The convenience sample of family caregivers was located through mailings distributed by local chapters of the Alzheimer's Association, the Michigan Association of Adult Day Care Centers, and health agencies in southwest Michigan. Caregiver/patient dyads enrolled in the study met the following criteria: (a) the patient was at least 55 years of age; (b) the patient was dependent in at least one instrumental activity of daily living (IADL) and one activity of daily living (ADL); (c) the patient had received a diagnosis of Alzheimer's disease or other progressive dementia; (d) the caregiver was self-identified as the family member providing the most care to the relative with dementia; and (e) the patient was residing in the community at the time of data collection (Collins et al., 1991).

From the overall sample, potential participants for the qualitative portion of the study were contacted by telephone and asked to participate in an in-depth interview that would focus on community service use. Inclusion criteria were related to (a) being located within a specific three county area, (b) their ability to respond verbally to questions, and (c) a willingness to be interviewed. All of the individuals who met the above criteria $(n=37)$ agreed to be interviewed. Three interview transcripts were not included in the analysis because two of the interview tapes were not audible due to the technical quality of the tapes and one subject had difficulty focusing responses on the topic of the interview. Because the geographic area was restricted for this subsample of caregivers, it was possible to analyze findings with the knowledge that the community services in question were present for all participants. Within these three counties 4 support groups, 4 adult day care programs, and 21 homecare agencies that provided home health aide services were available at the time interviews were conducted (Stommel, 1990). 


\section{Human Rights}

At the time they were contacted by telephone regarding participation in the interview caregivers were informed that the interview was in addition to their previous participation in the longitudinal study and was totally voluntary. The interview was described as being focused on the use of community services by the caregiver to assist in the care of their family member. Potential interview participants were informed that the interview would be scheduled at a time and place convenient to them, that it would take approximately one hour and that they were free to withdraw from the interview at any time without recrimination. Potential participants were also informed that they would be asked permission to audiotape the interview.

Assurances of confidentiality, along with information previously given about the interview and its purpose, were reviewed at the time of the scheduled interview. Interview participants were given an interview consent form to sign and permission to tape-record was verified verbally before beginning the interview. Individual and place names were not associated with any transcribed interview and were omitted from the transcription if they occurred on the tape recording of the interview. Interview tapes were erased following validation of the accuracy of transcripts.

\section{SAMPLE CHARACTERISTICS}

Interviews with 34 caregivers were used for this analysis. Of this group, $79.4 \%$ were female $(n=27)$ and $20.6 \%$ were male $(n=7)$. Half of the group $(n=17)$ were daughters or daughters-in-law with a mean age of 52.1 years. The other half of the sample was made up almost entirely of spouses $(n=16)$, who had a mean age of 71.2 years. One participant was a sibling whose age was 70 years. Half of the group $(n=17)$ reported that they were retired, $26.4 \%(n=9)$ worked full-time, $11.7 \%(n=4)$ worked part-time, and $11.7 \%$ reported that they had never worked outside of the home. These caregivers reported that they had been providing assistance to their relative from 1 to 10 years, with a mean of 3.7 years. Use status of caregivers for home health aides, adult day care, and family support groups was classified as user, past user, or never used and is displayed in Table 1. 
TABLE 1: Status of Community Service Use Among Study Participants $(n=34)$

\begin{tabular}{llll}
\hline & Current User & Past User & Never Used \\
\hline Home health aide & $16(47 \%)$ & $6(18 \%)$ & $12(35 \%)$ \\
Adult day care & $11(32 \%)$ & $2(6 \%)$ & $21(62 \%)$ \\
Support group & $13(38 \%)$ & $7(21 \%)$ & $14(41 \%)$ \\
\hline
\end{tabular}

\section{Data Collection}

In the qualitative interviews the caregivers were asked to recount their experiences with community services (home health aides, adult day care, and support groups) in the following areas: (a) as they first developed an awareness that their relative had a problem, (b) during the process of obtaining a diagnosis, and (c) through the course of the disease to the current moment. Interviews of from 1 to 1.5 hours were carried out in the caregivers' homes or at other sites convenient to them. Throughout the interview, participants were encouraged to describe the need they felt for assistance and the steps they took toward obtaining help. Specific open-ended questions that comprised the interview protocol are included in the appendix.

\section{Analysis}

Interviews were transcribed verbatim onto the Ethnograph computer program. The plan for analysis of interview data included the following two phases: content analysis and development of matrices to aid in the formation of propositions relating identified values to reported patterns of service use. Each transcript was examined for any comments that might be interpreted as reflecting the values of the interviewed caregiver. Following the isolation of all comments that indicated values of the caregiver, statements were reviewed by seven members of the research staff to identify clusters that exemplified specific identifiable constructs that become the coding categories. Three coding categories were identified: sense of family obligation, need for reciprocity, and need for control.

Responses coded in the family responsibility category included statements regarding the feelings of the caregiver about their sense that it was their personal responsibility to take care of any of the problems surrounding the caregiving situation. Responses that were coded as reciprocity included statements that indicated the caregivers need to give back in kind or pay financially for any assistances that were 
rendered in their caregiving responsibility. Responses coded as need for control consisted of statements that reflected the caregivers' requirement that they regulate and maintain supervision of some or all aspects of their relatives' care.

Following the development of coding categories, two researchers independently coded the transcripts and coding discrepancies were reconciled. Coded segments were registered on the computerized transcripts. Themes were identified from the coding categories using the procedures outlined by Miles and Huberman (1984). The presence and frequency of identified themes was independently verified by two researchers. Quotations were identified from the transcripts that characterized each theme.

\section{RESULTS}

Four themes were identified and verified from the coded transcripts: family boundries govern help seeking, families are owners of difficulties, families are protectors of vulnerable members, families are selfreliant units.

\section{Themes}

\section{Family Boundaries Govern Help Seeking}

Seven of the interviewed caregivers made specific statements about their sense of family obligation. The observed boundaries of the family system were described as being a part of one caregiver's understanding of how family problems are appropriately handled. "My father or my mother never told the children of any of their problems. They handled their own problems." This same caregiver described not only how her own parents had functioned to take care of her grandparents but also the unwillingness she had seen role modeled for the acceptability of assistance from outside the boundaries of the family. "Well, I could see my dad looking after his mother. I could see my mother looking after her mother when she needed help. So I did see my parents doing for others in the family. I never saw them doing much outside the home." This daughter had used home health aides and support groups for a short period of time, but no longer was doing so. Her mother currently attended a day care program two mornings a week. 


\section{Families Are Owners of Difficulties}

The feeling that the problems encountered belonged to the family unit and should not become problems for others was expressed by some caregivers. Other caregivers spoke in terms of how their learned family boundaries served to define the "ownership" of the problems that they confronted in taking care of their relative with Alzheimer's disease. One woman, whose husband had been diagnosed with Alzheimer's disease for 5 years, told us about her response at the time of his diagnosis and the acceptability of community service assistance in the following way: "At that time I hadn't even thought of consulting anybody for any help. I thought probably as, if he had this, it was up to me to retire and take care of him." This wife attended a support group regularly but had never used either adult day care or home health aides for assistance.

Another spouse caregiver, a wife who did use a home health aide but had never used any other community service, expressed a similar viewpoint when she said, "I was brought up that a husband and wife were supposed to go together. My father and mother liked the same things and wherever they went, they went together. I will not deprive my husband of anything he wants and he wants me to take care of him."

\section{Families Are Protectors of Vulnerable Members}

Caregivers who spoke of a value that reflected a need for control reported a need to believe that the care provided by others will be of the same kind and quality that they would provide themselves. One caregiver expressed this need when she said: "Loving, caring understanding of them [the patient]. It takes certain individuals to be able to cope with this type of thing. If you can get people that get trained enough like this, it's certainly a lot better because they know how to handle the problems right."

Additionally, the beliefs of the family member for whom care was being provided may substitute for or override the beliefs of the caregiver. Concern for the beliefs of her mother and her comfort with assistance from outside the family became the dominant value influencing one caregiver who reported: "Even in her dementated [sic] stage she is hesitant and is leery of strangers and by nature does not accept freely any help. My parents were very much their own people and very private-fiercely private." This daughter had never made 
use of any form of community service to aid in the care of her severely demented mother.

Control and trust were often mentioned in conjunction with one another and most frequently in statements that would point to the reasons why caregivers are cited as preferring to make use of informal sources of assistance rather than formal community services. One woman who made no use of services for her moderately demented mother said, "I trust my sister implicitly. She would do exactly what I would do in any situation, so I feel very comfortable with that ... I haven't investigated services because I feel so fortunate to have my family who are willing to help me."

A 78-year-old husband who has cared for his wife with early Alzheimer's disease for a year and a half without the aid of any community service talked about the strategy he would use if he were looking for assistance, "You just have to keep up with every contact you have and take advantage of it. I think you get better help that way than you probably would get through some agency who couldn't possibly have knowledge of the broad array of problems you've got."

Another caregiver who was reluctant to seek assistance from formal sources also explained her reluctance in terms of trust and her ability to control the behaviors of persons providing assistance. "You don't know who it is and you don't know how they will treat them (the Alzheimer's patient) when you are not there."

Caregivers concerns about their ability to control the caregiving situation sometimes moved beyond trust for the appropriateness of the care rendered and into a more comprehensive belief in the trustworthiness of other people. Some expressed a concern for the safety of the care recipient and their belongings. "It is hard to find trustworthy people because they have access to everything in the house. They could be thieves. You never know what they are going to do."

\section{Families Are Self-Reliant Units}

When caregivers talk about how easy it is for them to seek assistance another dimension of their personal values surfaced. Seven caregivers made statements about the importance of being able to tangibly reciprocate for the assistance they received in the care of their family member. Reciprocity was not necessarily described as part of the caregivers' family belief system but most certainly was introduced as a strong personal value. 
Reciprocity has been defined as the equivalent exchange of content in a relationship, wherein people attempt to maintain balanced exchanges in their relationships (Wentowski, 1981). In caregiving literature it has not been uncommon for the concept of reciprocity to be referred to when defining the motivation of people to take on the caregiving role. There have been frequent references to caregiver participation in providing care as their way to "pay back" the care recipient for past caring that they provided to the caregiver. In these interviews, however, another aspect of reciprocity surfaced. Caregivers did not wish to accept assistance from other people that they did not feel able to reciprocate.

One caregiver, a husband, stressed his need not to feel dependent on others when he said, "You hate to get dependent on people. I have a neighbor here and three neighbors across the road, and they've told me over and over to call if I need help. I've called them once in awhile, but I don't want to feel obligated to them." Although this man had tried using support groups and home health aides briefly, the only regular assistance that he had for the care of his severely demented wife was an adult day care program where he occasionally participated in scheduled activities.

A daughter described her inability to reciprocate assistance in looking after her mother in terms of "taking advantage" of the person making an offer of help. "For instance, a secretary offered to babysit. I would never, you know, take advantage of someone like that. I would feel like I was taking advantage. No, but I think maybe if you have really close people that you know and you could reciprocate with you could do that, but I don't."

The sense of need to be able to reciprocate for assistance received appears to define, at least for some caregivers, the extent to which assistance is most acceptable from formal or informal sources. Although many caregivers expressed that they preferred informal assistance, they frequently did not seek or accept informal help because of their inability to reciprocate that assistance. An example is a wife caregiver who made the following statement: "It is easy for me to hire it and get it done professionally. I don't have any problem with that. I have a real hard time, like asking the neighbor to do extra things. You know putting her out or asking the grandkids to spend extra time doing something when I know they are wanting to do things with friends."

Several other caregivers, both spouses and adult children, made reference to their need to "pay back," either in money or assistance, 
those who were involved in helping them. A characteristic comment was made by a daughter when she said, "I don't like to ask people to do things without reimbursing them and some of them wouldn't take anything for helping."

A rural woman who took care of her mother-in-law without the assistance of any community services described with pride the way she viewed her family and their independence, "We have had hardships. We have burned out, we have flooded out. You know, we have been there and we always come out on top ourselves and we never ask for help."

\section{Analysis of Themes}

After the themes were identified and categorized from interview transcripts a matrix was formulated to seek the relationship of expressed values with service use experiences. The technique of using matrix analysis is described by Miles and Huberman (1984). This matrix incorporated characteristics of the caregiver, level and type of service use, and category of value statements made by the caregiver.

\section{DISCUSSION}

Several conclusions may be reached from analysis of this qualitative data. Basic human values do influence the tendency of people to obtain help, either formal or informal, from outside the caregiver/ care recipient dyad but not always in ways that are easily predictable. It is important to reemphasize the point made by Ajzen and Fishbein (1980): that it is inappropriate to assume that values and beliefs may be used to predict behavior. If anything, attention to human values only serves to make the efforts to predict service use more complex. This discussion will focus on the following two areas: (a) consideration of the important interplay between formal and informal assistance to families and (b) discussion of the need for an increased sensitivity on the part of service providers to the value systems of the people they are trying to help.

This analysis suggests the importance of increased research into the understanding of how values are linked to the decision to provide exclusive assistance or to supplement caregiver efforts with informal assistance, formal assistance, or both. For those subjects who expressed primary concerns about "control" and "family obligation," 
the provision of care fell most comfortably within the confines of the family. When they sought assistance these study participants talked about help that they received from other members of their family rather than from formal services available in the community. Those who attended support groups reported that other family members frequently attended meetings with them.

Although "reciprocity" was a value expressed by many of the study participants who were interviewed, the defining characteristics of this need for independence did not mean that the caregiver found it essential to provide exclusive care. Instead, these caregivers portrayed a need to obtain assistance in ways that did not result in feelings of personal obligation or dependence on others. Several stated in very clear terms that they were more comfortable in gaining assistance from those whom they could pay for their service than from friends or relatives who would not accept reimbursement.

Probably values are one of the most difficult areas that providers may attempt to assess. When asked directly about the values they held with regard to using assistance from outside the home, caregivers were unable to articulate responses. Because there is a need for sensitivity on the part of service providers to the values of potential clients, it is important to know how to evaluate that facet of their personality.

When study participants did make statements reflective of their values they tended to do so in response to questions such as "How would you describe yourself (your family)?" "Where do you get help with the caregiving that you are doing?" "How difficult is it for you to ask for help?" and "What do you know about (a specific category of service)?"

Services that are targeted toward assisting people in the care of their family members may bypass many individuals who would benefit from them unless attention is paid to the basic values that influence those individuals. If caregivers believe that the problems that accompany care of their relatives are "owned" by the family unit it becomes imperative that education about available services be targeted to the whole family unit rather than only the caregiver.

Active family involvement in service planning and on boards of service-providing agencies are activities that may result in trust building while acknowledging the dignity of the caregiver. Services that allow for caregiver involvement in planning, implementation of planned activities, or both recognize the need of family members to handle the problems they encounter while giving them the opportu- 
nity to have assistance with those situations. Most vital is the acknowledgment by service providers that there is no single "right way" to provide care for relatives, but that there is a way that is right for each family unit.

\section{APPENDIX \\ Interview Guide \\ Use Of Community Services By Alzheimer's Caregivers}

The reason for this interview is to get a detailed picture of your experience taking care of a person with Alzheimer's disease. We would like to know as much as possible about what kinds of help you need now or may have needed at times in the past. I'm interested in knowing what experiences you may have had in looking for help and what things you think are important for service providers to know when they are planning services for people in situations like yours.

A. First Awareness: I would like to start out by talking about the history of your relative's Alzheimer's disease and the events leading up to your awareness of the disease.

1. Describe the situation when you first noted difficulties or what you think was the beginning of the Alzheimer's disease.

a. How were you spending time? What was happening in your life at the time?

b. How did you first suspect that something was wrong?

c. What did you do before going to the doctor? Did you ask for or receive advice from friends or family?

d. Tell me about the experience you had getting a diagnosis for your (parent/spouse). Was s/he diagnosed as having Alzheimer's disease the first time that you went to the doctor?

e. What was your reaction to finding out that your (parent/spouse) had Alzheimer's disease?

f. What did you know about Alzheimer's disease at the time your (parent/spouse) was diagnosed? Had you ever known anyone else who had it?

g. What did you need in the way of help when your (parent/spouse) was first diagnosed?

h. What help did you seek at that time?

i. How did you go about finding that help?

j. What help did you think about seeking but didn't? What prevented you? 
2. Help-seeking patterns. I am interested in knowing more about the ways that you have gotten the kind of help for other problems that you may have had in the past.

a. Other times, has it been easy for you to ask for help from others?

b. What kind of help can you ask for?

c. What kind of help can you not ask for?

d. How does it make you feel when you face a situation that is so difficult to handle that you need to seek help from others?

3. Could you please describe yourself and your relationship with the patient before the problems with Alzheimer's disease began.

B. Through the Course of the Disease: People with Alzheimer's disease go through a lot of changes. I'm interested in knowing more about what those changes have been for your (parent/spouse) and how they have affected you.

a. As time progressed, what changes occurred in your (parent/spouse) as a result of the Alzheimer's disease?

b. How did the demands of caregiving change for you as the disease progressed?

c. How did your life change as the Alzheimer's disease became more severe?

d. What else was going on in your life at the same time (besides taking care of the patient)?

e. Describe the feelings you had as your patient developed different symptoms of Alzheimer's disease. Were there times that you felt embarrassed? Inadequate? Afraid?

f. Did your feelings affect your ability or willingness to ask for help?

g. When did you first seek some kind of assistance with the care of your (parent/spouse)?

h. What kind of assistance was that? How did you know about that particular service? What did it cost for you to use it?

i. What prompted you to look for assistance at that time?

j. What did you get out of the service you used? How did they help your (parent/spouse)? How did they help you?

k. What were the disadvantages? How did it make you feel?

1. Tell me all of the good things and the bad things about the services that you used to help you take care of your (parent/spouse).

C. View From the Current Moment: You have told me about what it was like when your (parent/spouse) first developed Alzheimer's disease and the things that have taken place since that time. I'm also interested in what it is like for you right now and how you think things may change in the future. 


\section{APPENDIX Continued}

1. What services are you using to help you take care of your (parent/spouse) right now?

a. How much help are those services to you?

b. What would make them better?

c. How did you locate these services?

2. Looking back, if you could have found just what you needed to make this whole experience easier for you, when would that have occurred?

a. What would it have looked like?

b. Would you have used it?

3. What are the most important areas, from your perspective, that people like you need assistance with?

a. Is there a "right time" and a "wrong time" for certain kinds of services? (ask for examples)

b. What kinds of things kept you from using services when you might have needed them?

D. Specific Services: The things that you need to help you change over time and so do the things that you expect from different kinds of services. These questions are about what you have experienced with several different sorts of services. Answering the questions about some of these services may make you feel like you are repeating yourself. If that is the case, could you just summarize your experiences with the service?

1. Describe your experience with the following kinds of services; What do you know about them? Have you used them? Did they help?
a. Visiting nurses
b. Home health aides
c. Adult day care
d. Home companions/sitters
e. Family support groups
f. Housekeeping/chore services

2. What advice would you give other families about getting help?

3. Is there anything else that we should understand about how community services do and do not help you that hasn't been touched upon by any of the questions? 


\section{REFERENCES}

Ajzen, I., \& Fishbein, M. (1980). Understanding attitudes and predicting social behavior. Englewood Cliffs, NJ: Prentice-Hall.

Allport, G. W. (1935). Attitudes. In C. Murchinson (Ed), A handbook of social psychology. Worchester, MA: Clark University Press.

Anderson, R., \& Newman, J. (1973). Societal and individual determinants of medical care utilization in the United States. Milbank Memorial Fund Quarterly, 51(1), 95-124.

Bass, D., \& Noelker, L. (1987). The influence of family caregivers on elder's use of in-home services: An expanded conceptual model. Journal of Health and Social Behavior, 28(2), 184-196.

Branch, L., Jette, A., Evashwick, C., Polansky, M., Rowe, G., \& Diehr, P. (1980). Toward understanding elders' health service utilization. Journal of Community Health, $7(2)$, 80-92.

Collins, C., Stommel, M., King, S., \& Given, C. (1991). Assessment of the attitudes of family caregivers toward community services. The Gerontologist, 31(6), 756-761.

Given, C., Collins, C.. \& Given, B. (1988). Sources of stress among families caring for relatives with Alzheimer's disease. Nursing Clinics of North America, 23(1), 69-82.

McCaslin, R. (1988). Reframing research on service use among the elderly: An analysis of recent findings. The Gerontologist, 28(5), 592-598.

McPherson, B. (1990). Aging as a social process. Toronto: Butterworths.

Miles, M., \& Huberman, A. (1984). Qualitative data analysis. Newbury Park, CA: Sage.

Stommel, M. (1990). Survey of home health agencies in Ingham, Eaton and Clinton Counties, Michigan [Unpublished report]. East Lansing: Michigan State University.

Wentowski, G. (1981). Reciprocity and the coping strategies of older people: Cultural dimensions of network building. The Gerontologist, 21, 600-609.

Sharon King, R.N., C.S., Ph.D., is a clinical specialist in gerontological nursing and an associate professor in the College of Nursing at Michigan State University.

Clare Collins, R.N., Ph.D., F.A.A.N., is a clinical specialist in mental health nursing and a professor in the College of Nursing at Michigan State University.

Michelle Liken, R.N.C., M.S.N., has a clinical master's degree in gerontological nursing from Michigan State University and is a doctoral student at the University of Michigan. 